\section{Influence of Nonpermanent Netting on Foliar Spray Deposition, Insect Pest Prevalence, and Production of 'Nadorcott' Mandarin (Citrus reticulata)}

\author{
Ockert P.J. Stander ${ }^{1}$ and Jade North \\ Citrus Research International, P.O. Box 28, Nelspruit, 1200, South Africa; \\ and Citrus Research International, Department of Horticultural Science, \\ University of Stellenbosch, Private Bag X1, Matieland, 7602, South Africa
}

Jan M. Van Niekerk

Citrus Research International, P.O. Box 28, Nelspruit, 1200, South Africa; and Citrus Research International, Department of Plant Pathology, University of Stellenbosch, Private Bag X1, Matieland, 7602, South Africa

Tertia Van Wyk

Department of Plant Pathology, University of Stellenbosch, Private Bag X1, Matieland, 7602, South Africa

Claire Love and Martin J. Gilbert

Citrus Research International, P.O. Box 28, Nelspruit, 1200, South Africa; and Citrus Research International, Department of Conservation Ecology \& Entomology, University of Stellenbosch, Private Bag X1, Matieland, 7602, South Africa

Additional index words. False codling moth, fruit quality, fruit yield, leaf mineral nutrients, fruit fly, shade netting

Abstract. This study aimed to determine the effects of different types of nonpermanent netting (NPN) on foliar spray deposition, insect pest prevalence, and production and fruit quality of 'Nadorcott' mandarin (Citrus reticulata) trees in a commercial orchard at Citrusdal (lat. 32 32' 31"S, long. $190^{\prime} 42^{\prime \prime} E$ ), Western Cape, South Africa. The deposition quantity (FPC\%) of foliar spray volumes of 3500,7000 , or $15,000 \mathrm{~L} \cdot \mathrm{ha}^{-1}$ was greater for leaves of control trees compared with leaves treated with NPN during summer (January) $(8.8$ vs. 6.1; $P=0.0055)$ and winter (June) (4.8 vs. 3.1; $P=\mathbf{0 . 0 0 3 5})$. Deposition uniformity $(\mathrm{CV} \%)$ was better for control leaves during summer (64.9 vs. $75.2 ; P=0.0062)$ and winter $(59.6$ vs. $80.5 ; P=0.0014)$, and deposition quality $(\mathrm{ICD} \%)$ was better during winter $(79.4$ vs. $84.2 ; P=0.0393)$. There were no differences in FPC\%, CV\%, and ICD\% for fruit when foliar spray volumes of 3500 and 15,000 $\mathrm{L} \cdot \mathrm{ha}^{-1}$ were used for the control and NPN treatment groups during winter. However, with a foliar spray volume of $7500 \mathrm{~L} \cdot \mathrm{ha}^{-1}$, fruit from the control treatment group had greater $\mathrm{FPC} \%$ (19.3 vs. 6.1; $P=0.0262), C V \%$ (70.3 vs. 50.9; $P=0.0484)$, and ICD\% (57.1 vs. 79.9; $P=0.0157)$. There were no differences in macronutrient concentrations between the leaves of trees subjected to control and NPN treatments, but leaf zinc $(<81 \% ; P=0.0317)$ and iron $(<78 \% ; P$ $=0.0041)$ concentrations were lower with the NPN treatment. During short NPN treatments, fruit yield was reduced by $\approx 37 \%$ compared with that after control treatment, and longer NPN treatments had no effect on fruit yield. The reduction in fruit yield with NPN was not related to the effects of NPN on foliar spray deposition or to lower leaf micronutrient concentrations. The lower fruit yield during short NPN treatments was most likely caused by fruit drop that was exacerbated by the removal of the NPN. In the long NPN treatment group, fruit damage caused by sunburn was reduced by $17 \%$, but the outer canopy fruit experienced increased wind damage or scarring. Except for the lower titratable acidity content with the shortest NPN treatment and the higher Brix $^{\circ}$ :TA ratio with two NPN treatments, NPN did not impact other fruit quality attributes. The use of NPN excluded male wild false codling moths (Thaumatotibia leucotreta) (FCM) males; however, it was still possible to capture a very small amount of mass-released sterile FCM and wild fruit flies under the NPN.

The use of protective netting in fruit tree cultivation is an effective method of preventing yield loss that can result from high temperatures and irradiation, strong wind, and hail (Manja and Aoun, 2019; Mupambi et al., 2018; Raveh et al., 2003; Stamps, 2009; Wachsmann et al., 2014). Often, the use of protective netting also results in changes in the orchard microclimate that can alter tree physiology and improve tree performance and fruit development (Cohen et al., 2005; Manja and Aoun, 2019; Mupambi et al., 2018; Pérez et al., 2006; Raveh et al., 2003; Stamps, 2009; Wachsmann et al., 2014; Zhou et al., 2018). Various different types of permanent protective netting structures and/ or different colors of shade netting have been tested to determine their effects on tree physiology and fruit development and quality (Manja and Aoun, 2019; Mupambi et al., 2018; Stamps, 2009; Wachsmann et al., 2014; Zhou et al., 2018). In Citrus spp., nonpermanent netting (NPN) is used in certain production regions during a particular stage of the season to protect trees and fruit from damage that could be caused by hail (Wachsmann et al., 2014). It is also used for some citrus cultivars during flowering to exclude bees, thereby preventing crosspollination and unwanted seed development (Gambetta et al., 2013; Gravina et al., 2016; Otero and Rivas, 2017).

Certain citrus cultivars have the ability to produce fruit without the flower having to be pollinated or the ovaries having to be fertilized, which is known as parthenocarpy (Mesejo et al., 2016). A cultivar such as Nadorcott mandarin (C. reticulata), for example, is an obligate parthenocarp (Gambetta et al., 2013), which means its ovaries can produce sufficient gibberellins during anthesis to produce fruit in the absence of pollination (Mesejo et al., 2016). 'Nadorcott' mandarin is also sexually selfincompatible (Gambetta et al., 2013; Nadori, 2006), which means that its flowers are unable to produce seed on self-pollination (De Nettancourt, 1977). This trait is advantageous for commercial citrus production because when trees are isolated from certain potential crosspollinators, they can produce seedless fruit (Gambetta et al., 2013; Otero and Rivas, 2017), which are preferred by the market and sold at a premium (Barry, 2006).

It is not always possible to avoid crosspollination during commercial citrus production. When flowers of 'Nadorcott' mandarin are exposed to pollen from a different compatible cultivar, the fruit are normally seeded (Nadori, 2006; Wright, 2007), thereby reducing the market value of the fruit (Barry, 2006). During commercial 'Nadorcott' mandarin production, for which the potential for cross-pollination is high and seed development likely, some growers cover the entire tree with NPN during flowering to exclude pollinators such as honeybees (Gravina et al., 2016; Otero and Rivas, 2017). This method is successful and environmentally safe. However, it is unclear how the covering of trees with NPN before, during, and after flowering for an extended period, thereby affecting tree growth and fruit development, impacts the deposition of foliar sprays that are applied and fruit production.

This study evaluated the effects of NPN on foliar spray deposition, leaf mineral nutrient concentration, fruit yield and quality, and rind surface damage of 'Nadorcott' mandarin fruit. Monitoring of two important 
insect pest species was performed during the experiment to determine the effect of NPN on their numbers. The false codling moth (FCM), Thaumatotibia leuctotreta (Meyrick) (Lepidoptera: Tortricidae), is a well-known pest of the South African citrus industry that causes crop losses due to larval infestation of fruit (Newton, 1998; Moore and Hattingh, 2012). Furthermore, the FCM is classified as a phytosanitary pest by a number of export markets (Grout and Moore, 2015). Therefore, it is important to monitor and control this pest. The Mediterranean fruit fly, Ceratitis capitata Weidemann (Diptera: Tephritidae), is a highly polyphagous species that uses citrus as a host (Du Toit, 1998; Grout and Moore, 2015). Economic losses may occur either as a direct result of female fruit fly oviposition and larval infestation or due to the phytosanitary status of $C$. capitata, which can result in the rejection of infested fruit from sensitive export markets.

\section{Materials and Methods}

\section{Plant material and experimental site}

The study was conducted in a commercial orchard of 6-year old 'Nadorcott' mandarin trees budded onto 'Carrizo' citrange ( $C$. sinensis $\times$ Poncirus trifoliata) rootstock at Citrusdal (lat. 32 32'31" S, long. $190^{\prime} 42^{\prime \prime} \mathrm{E}$ ) in the Western Cape province of South Africa. The region is semi-arid and experiences typical Mediterranean-type climate conditions. Summer occurs from December to February, autumn occurs from March to May, winter occurs from June to August, and spring occurs from September to November. The region receives an annual rainfall that ranges between 400 and $650 \mathrm{~mm}$, of which the majority occurs from the end of autumn to the end of winter (May to August). Trees were planted in sandy soil with spacing of $5.5 \times 2.5 \mathrm{~m}$, resulting in 727 trees per hectare; the orchard is orientated in a northsouth row direction. The selected orchard was bordered on the north and south sides by 'Nadorcott' mandarin trees and on the east and west by 'Navel' sweet orange trees at distances of $\approx 200$ and $400 \mathrm{~m}$, respectively. The nearest potential cross-pollinator was 'Nules Clementine' mandarin trees located $\approx 900 \mathrm{~m}$ to the south.

Trees were irrigated using a drip system with four emitters per tree, and the total water supply was $\approx 8000 \mathrm{~L}$ per tree per year. All trees received consistent and standard fertilizer applications; the rate of application $\left(\mathrm{kg} \cdot \mathrm{ha}^{-1}\right)$ was based on annual leaf mineral nutrient analysis and a target fruit yield of 60

Received for publication 20 Nov. 2018. Accepted for publication 17 Jan. 2019.

We thank CP Mouton and Conrad Vorster for allowing access to their orchard at Houtkaprug in Citrusdal, and Citrus Research International (Pty) Ltd and the Department of Science and Technology (SIF-RCE) for financial support. We also express our appreciation to Drape Net SA (Pty) Ltd for providing the nets.

${ }^{1}$ Corresponding author. E-mail: jakkie@sun.ac.za. to 70 ton per hectare. Micronutrients were mostly applied in the form of low-volume foliar spray applications from early spring to late summer, and macronutrients were mostly applied via the soil (fertigation). Foliar application of gibberellic acid $\left(\mathrm{GA}_{3}\right)$ [Progibb ${ }^{\circledR}$ $40 \%$ soluble granule (SG) formulation containing $400 \mathrm{~g} \cdot \mathrm{kg}^{-1}$ a.i. of $\mathrm{GA}_{3}$; Valent BioSciences Corporation, Libertyville, IL] was used for all treatments at $80 \%$ petal drop in Oct. 2017.

\section{Experimental design and treatments}

The experiment comprised a completely randomized design and included an untreated control (i.e., open trees without NPN) and three different NPN treatments. The following NPN treatments were applied before flowering in Aug. 2017, with a score of 51 on the Citrus BBCH phenological scale (Agustí et al., 1997): trees were covered with NPN from Aug. 2017 to Nov. 2017 (NPN August to November); trees were covered with NPN from Aug. 2017 to Mar. 2018 (NPN August to March); and trees were covered with NPN from Aug. 2017 until harvest in July 2018 (NPN August to July). Each treatment consisted of four replicates $(n=4)$ that were applied to entire tree rows. Trees were covered to the ground with a white ( $18 \%$ shade) AHN$55\left(55 \mathrm{~g} \cdot \mathrm{m}^{-2}\right)$ mesh NPN (Drape Net SA, Johannesburg, South Africa). During each treatment replicate, two data trees were used to determine the effects of treatments on fruit yield, fruit quality, leaf mineral nutrient concentration, and fruit surface damage $(n=8)$. To determine the effects of treatments on foliar spray deposition, three data trees within each treatment replicate were used.

\section{Data collection}

Foliar spray deposition. To evaluate the effects of NPN on the deposition of foliar sprays in the tree canopy, the control and NPN treatments were sprayed in Jan. 2018 (summer) and in June 2018 (winter) with different water volumes of commercial foliar sprays using a $2000-\mathrm{L}$ oscillating spray machine (Nieuwoudt Spray, Citrusdal, South Africa). The January foliar sprays were applied at water volumes of 3500 and 15,000 $\mathrm{L} \cdot \mathrm{ha}^{-1}$. The June sprays were applied at water volumes of 3500,7000 , and $15,000 \mathrm{~L} \cdot \mathrm{ha}^{-1}$. Each foliar spray contained fluorescent pigment [South Australian Research and Development Institute (SARDI) Yellow Fluorescent Pigment, 40\% EC (SARDI, Loxton, South Australia)], thereby allowing for visualization of spray deposition on the leaf and fruit surfaces after spray applications. The pigment dosage was adjusted according to the respective spray volumes of 1,2 , and $3 \mathrm{~mL} \cdot \mathrm{L}^{-1}$ of pigment that were added to $15,000,7000$, and $3500 \mathrm{~L} \cdot \mathrm{ha}^{-1}$ of foliar spray. Foliar sprays were applied to both sides of 10 adjacent trees in single rows of NPN and control treatment replicates. Leaves and fruit were sampled from three randomly selected uniform trees within the respective treatment replicates. For the January evaluation, only leaves were sampled; however, fruit and leaves were sampled for the June evaluation. Samples were collected after the application of the foliar sprays from different tree canopy positions: three vertical positions (top, middle, and bottom) and two horizontal positions (inner canopy, which comprised leaves 30 to $50 \mathrm{~cm}$ inside the tree canopy and in the top, middle, or bottom of the tree canopy; outer canopy, which comprised leaves or fruit on the outside of the top, middle, or bottom of the tree canopy). From each position, 12 leaves (for a total of 72 leaves per data tree) were collected and transported to the laboratory in labeled plastic bags. Fruit were sampled from the same positions as those used for leaves. Five fruit were sampled from each position, with a total of 30 fruit per data tree. The side of the fruit that faced the spray machine was marked with a permanent marker before the fruit were sampled and placed in labeled carton containers and transported to the laboratory. The leaves and fruit were stored at $4{ }^{\circ} \mathrm{C}$ until deposition analysis was conducted as described by Van Zyl et al. (2013). Images of leaves and fruit were captured in a dark room with an illuminated ultraviolet light source (ultraviolet-A, $\approx 365 \mathrm{~nm}$, Labino Mid Light; www.labino.com). A red Perspex box $(300 \times$ $210 \times 110 \mathrm{~mm}$ ) was used to reduce any shadowing and to enhance the edges of leaves. A glass pane $(200 \times 200 \times 2 \mathrm{~mm})$ was used to cover leaves, and fruit were placed on a small plastic stand. A camera (Canon EOS 40D; Canon, Tokyo, Japan) equipped with a $60-\mathrm{mm}$ macro lens was used to capture digital images in RAW file format (.CR2 $\approx 10 \mathrm{MB}$ ) of the upper leaf, lower leaf, and fruit surfaces. Digital images of the fruit surface that faced the spray machine and of the fruit surface that faced away from the spray machine were captured. The camera was mounted on a tripod in a fixed position above the Perspex box. RAW images were converted to 8-bit ExifTIFF (.TIF $\approx 30 \mathrm{MB}$ ) format using Digital Photo Professional software version 3.1.0.0 (Canon Inc.; www.canon.com) to determine the deposition parameters using digital analysis (Van Zyl et al., 2013). For leaves, a camera aperture setting of F10 and an ISO setting of 100 were used. An aperture setting of F14 and an ISO setting of 160 were used for fruit.

Deposition quantity was measured as the percentage of leaf or fruit area that was covered by pigment particles, otherwise known as the percentage fluorescent particle coverage (FPC\%). To perform deposition quality assessment, the leaf or fruit areas were divided into equal squares of $100 \times$ 100 pixels $(10,000$ pixels $)$. The area size of the leaf or fruit was between 20 and 250 individual squares per leaf. Therefore, the squares could be used to calculate the percentage area of the fruit or leaf surface that was covered by fluorescent pigment particles, independent of the size of the leaf or fruit. The percentage of the interquartile coefficient of dispersion (ICD\%) for each leaf or fruit was used as a measurement of deposition quality (i.e., the uniformity of deposition on the leaf or fruit surface). Low ICD\% 
values were indicative of better deposition quality. Deposition uniformity between leaves or fruit was calculated as the uniformity in pigment deposition in a batch of 12 leaves or 5 fruit (standard deviation $\times 100$ / mean). Deposition efficiency was expressed as deposition quantity normalized to $\mathrm{FPC} \%$ per $1000 \mathrm{~L}$ of water per hectare.

Insect pest prevalence. FCM was monitored using a yellow Delta trap that contained a sticky floor and a pheromone lure (Chempac, Simondium, South Africa) to attract males. The Mediterranean fruit fly, Ceratitis capitata Weidemann (Diptera: Tephritidae), was monitored using a Sensus trap (River Bioscience, Port Elizabeth, South Africa) that contained a Capilure (trimedlure) capsule and a small dichlorvos-impregnated block to attract and kill male fruit flies. One trap of each type was placed in the tree canopy in the control group, NPN August to March replicate, and NPN August to July replicate. The insect pest prevalence in the NPN August to November treatment group was not monitored because the insect lures were only available soon before the end of November. Nevertheless, fruit resulting from this treatment were evaluated for insect damage and/or insect infestation at the time of commercial harvest. Trap examinations were performed at 2-week intervals. FCM lures in traps were replaced every 3 months, and fruit fly lures were replaced every 6 weeks. The farm was included in the commercial areawide sterile insect release program [Xsit (Pty.) Ltd, Citrusdal, South Africa], during which sterile male FCM releases are conducted aerially on a weekly basis as part of an integrated pest management program. Therefore, both wild and sterile FCM males were monitored by traps.

Leaf mineral nutrient concentration. Leaves were sampled according to the South African citrus industry standard, specifically from 4- to 6-month-old fruiting shoots in March (Du Plessis et al., 1992; Du Plessis and Koen, 1992). One leaf sample consisted of eight leaves that were collected from four shoots between 0800 and 1000 HR on 1 Mar. 2018, from the same treatment replicates that were used to determine effects on fruit yield and quality. After sampling, the leaves were kept cool and washed with distilled water before being frozen at $-80{ }^{\circ} \mathrm{C}$ and freezedried (Christ Beta 1-8 LD Freeze Dryer; Martin Christ Gefriertrocknungsanlagen GmbH, Osterode am Harz, Germany). The leaves were ground to a fine powder with an analytical grinder (Yellow line, A10; IKAWerke, Staufen, Germany) and stored at $-80{ }^{\circ} \mathrm{C}$ until analysis. Mineral nutrient analyses of leaf samples were conducted by an accredited commercial chemical and microbiology analytical laboratory [Bemlab (Pty) Ltd., Strand, South Africa] according to published protocols (Hou and Jones, 2000). Briefly, $1 \mathrm{~g}$ of dried leaf tissue was ashed at $800{ }^{\circ} \mathrm{C}$ and made into a volume of $50 \mathrm{~mL}$ with a 50:50 hydrochloric acid (50\%) solution extracted through filter paper. The mineral nutrient concentrations were analyzed using inductively coupled plasma emission spectroscopy (Varian PRX-OEX; Varian Inc., Palo Alto, CA) according to suitable standards and after a nitric-hydrochloric total acid digestion step. To analyze total nitrogen $(\mathrm{N}), 0.15 \mathrm{~g}$ of each sample was combusted at $850{ }^{\circ} \mathrm{C}$ and analyzed using a LECO $\mathrm{N}$ analyzer (LECO FP528 Nitrogen analyzer; LECO Corp., St. Joseph, MI) and thermal conductivity. The concentrations of the mineral nutrients in the leaf were expressed as $\mathrm{mg} \cdot \mathrm{g}^{-1}$ leaf dry weight (DW) for macronutrients or $\mathrm{mg} \cdot \mathrm{kg}^{-1}$ leaf DW for micronutrients.

Fruit yield. Commercial fruit harvest commenced at the end of July 2018, when fruit quality indices complied with specifications established by fruit export markets determined by the minimum export standards and requirements for soft citrus (DAFF, 2015). Harvesting was completed by the end of August. To determine the total fruit yield of the respective treatments, fruit from two individual trees within each treatment replicate row were harvested separately on the same day, before the start of commercial harvest, and the total fruit yield was determined for each replicate ( $\mathrm{kg}$ of fruit per tree). A sample of 50 fruit was randomly collected from each replicate, and the transverse diameter $(\mathrm{mm})$ of each fruit was measured using an electronic fruit size-measuring caliper (CD-6" C; Mitutoyo Corp., Tokyo, Japan). Each fruit was assigned to a fruit size category, of which the average fruit weight was determined and fruit size distribution from each treatment replicate was extrapolated to determine the total fruit yield per tree (number of fruit per tree).

Fruit quality. To determine the effects of treatments on fruit quality attributes such as fruit size (diameter), total soluble solids $\left(\right.$ Brix $\left.^{\circ}\right)$ of the juice, titratable acidity (TA) of the juice, and fruit juice content $(\%)$, a sample of 12 randomly selected fruit was collected from the two individual trees within each treatment replicate row that were used to determine fruit yield. Fruit diameter was measured using an electronic caliper. The fruit were cut longitudinally to evaluate treatment effects on internal quality and any presence of seeds. A citrus fruit juicer (Sunkist $^{\circledR}$, Chicago, IL) was used to extract the juice from each fruit so that the juice percentage $(\%)$ could be calculated by dividing the weight of the juice by the total fruit weight. A refractometer (PR-32 Palette; Atago Co., Tokyo, Japan) was used to measure the total soluble solids content as Brix ${ }^{\circ}$, and TA was measured (888 Titrando; Metrohm AG, Herisua, Switzerland) and expressed as the percent of citric acid. The sugar-to-acid ratio was calculated by dividing the Brix $^{\circ}$ by the citric acid (TA) content (Brix ${ }^{\circ}$ :TA).

Fruit surface damage. Fruit surface damage evaluations were performed at the time of commercial harvest in July 2018 for the same fruit that were used for fruit quality evaluations. Fruit were examined for sunburn damage, light or severe wind damage, and any evidence of pest damage or chemical burn. Wind scarring of citrus is caused by young fruit coming into prolonged repetitive contact with parts of the tree vegetative structure such as leaves and twigs. Wind scarring can be a major source of downgrading of citrus fruit and varies depending on the climate of the area where the crop is grown (Bedford 1998). Light wind damage was defined as surface scarring equivalent to plates 1 and 2 of the Capespan citrus culling standards (still suitable for export), whereas severe wind damage was defined as equivalent to plates 3-6 (unsuitable for export). The wind damage categories may have included damage that was caused by abrasion of the fruit by the NPN because it was impossible to distinguish between damage caused by wind and damage caused by NPN scarring.

\section{Statistical analysis}

Statistica data analysis software version 14 (Dell Inc., Round Rock, TX) was used to analyze the fruit yield, fruit quality, and leaf mineral nutrient concentration data. Analyses of variance (ANOVA) were performed and mean separations were performed using Fisher's least significant difference test when applicable $(P \leq 0.05)$. Deposition quantity (FPC\%), deposition quality (ICD\%), and deposition uniformity $(\mathrm{CV} \%)$ data for the different spray volumes and NPN (covered or open) treatment combinations were subjected to ANOVA using SAS version 8.2 statistical software (SAS Institute Inc., 1999). The Student's $t$ test for the least significant difference $(P \leq 0.05)$ was used. The skewing effect of outliers was negated by using median FPC\% values of the 12 leaves or 5 fruit for deposition analysis. Data from upper and lower leaf surfaces were analyzed separately, but they were combined when describing the results.

\section{Results}

Foliar spray deposition. The January foliar spray deposition analysis of leaves showed a significant interaction between foliar spray volume and horizontal canopy position of leaves for deposition quantity (FPC\%) $(P<0.0001)$, deposition uniformity $(\mathrm{CV} \%)(P=0.0004)$, and deposition quality (ICD\%) $(P=0.0028)$ (not shown). NPN treatment (covered vs. open) had a significant effect on FPC $\%(P=0.0055)$ and $\mathrm{CV} \%(P=$ $0.0062)$. For ICD $\%$, this effect was nonsignificant $(P=0.1207)$ (not shown).

The interaction between foliar spray volume and horizontal canopy position showed that the $3500 \mathrm{~L} \cdot \mathrm{ha}^{-1}$ foliar spray volume resulted in an FPC\% of 9.6 on leaves on the outside of the tree canopy. This was similar to the $\mathrm{FPC} \%$ of the $15,000 \mathrm{~L} \cdot \mathrm{ha}^{-1}$ foliar spray volume, irrespective of horizontal canopy position of leaves $(\mathrm{FPC} \%$ inside $=8.5$; FPC $\%$ outside $=8.8$ ). The $3500 \mathrm{~L} \cdot \mathrm{ha}^{-1}$ foliar spray volume resulted in an FPC $\%$ of 2.8 on leaves on the inside of the tree canopy. This was significantly lower than the FPC\% of the $15,000 \mathrm{~L} \cdot \mathrm{ha}^{-1}$ foliar spray volume at the different horizontal canopy positions.

The CV\% results showed that the 15,000 $\mathrm{L} \cdot \mathrm{ha} \mathrm{a}^{-1}$ foliar spray volume resulted in the best 
application uniformity on leaves on the outside of the tree canopy (CV\% of 45.8), which was similar to the results of the same application for leaves on the inside of the canopy (CV\% of 50.2). These values were significantly better (lower CV\%) than the $\mathrm{CV} \%$ for the $3500 \mathrm{~L} \cdot \mathrm{ha}^{-1}$ foliar spray volume. For the $3500 \mathrm{~L} \cdot \mathrm{ha}^{-1}$ foliar spray volume, the $\mathrm{CV} \%$ on leaves at the inside of the canopy was 108.1, and at the outside of the canopy it was 76.3 $\mathrm{CV} \%$; these two values were significantly different.

The best deposition quality (lowest ICD\%) was observed on leaves on the inside of the tree canopy with the $15,000 \mathrm{~L} \cdot \mathrm{ha}^{-1}$ foliar spray volume (ICD\% of 59.5). For leaves on the outside of the tree canopy, the $15,000 \mathrm{~L} \cdot \mathrm{ha}^{-1}$ foliar spray volume resulted in an ICD $\%$ of 66.1, which was significantly poorer compared with the ICD\% for leaves on the inside of the tree canopy. However, the $3500 \mathrm{~L} \cdot \mathrm{ha}^{-1}$ foliar spray volume resulted in similar ICD $\%$ on leaves on the inside and outside of the tree canopy (64.4 vs. 61.7 ICD\%, respectively).

For the January foliar spray deposition analysis, the greatest FPC $\%$ was observed on control leaves of NPN treatments (8.8 and 6.1 $\mathrm{FPC} \%$, respectively), regardless of foliar spray volume (Table 1). Similarly, foliar spray volume had no influence on $\mathrm{CV} \%$, although it was significantly better for leaves of the control treatment group compared with leaves subjected to NPN treatments (64.9 and $75.2 \mathrm{CV} \%$, respectively) (Table 1). There was no significant difference in the ICD $\%$ for leaves of the NPN treatment groups and control group (64.4 and $61.5 \mathrm{ICD} \%$, respectively) (Table 1 ).

The June leaf deposition analysis indicated that there was a significant interaction between foliar spray volume and vertical and horizontal canopy positions for FPC\% ( $P=$ 0.0062 ). The reason for this interaction was most likely due to the $3500 \mathrm{~L} \cdot \mathrm{ha}^{-1}$ spray volume having significantly lower $\mathrm{FPC} \%$ values at the different horizontal and vertical canopy positions compared with the other two spray volumes. However, keeping in mind the aim of the study, the significant NPN treatment effect (covered vs. open) was more important $(P=0.0035)$. For $\mathrm{CV} \%$, the analysis showed a significant interaction between the foliar spray volume and vertical tree canopy position of leaves $(P=0.0043)$, as well as a significant relationship between the foliar spray volume and horizontal canopy position of leaves $(P=0.0002)$. The different spray volumes resulted in mean $\mathrm{CV}$ $\%$ values at the different vertical canopy positions that were between $54.4 \mathrm{CV} \%$ and 99.8 CV\%. Similarly, the mean CV\% resulting from the different spray volumes at the different horizontal canopy positions ranged from $48.3 \mathrm{CV} \%$ to $86.6 \mathrm{CV} \%$. The significant NPN treatment effect (covered vs. open) $(P=0.0014)$ was important for $\mathrm{CV}$ $\%$. Results for ICD\% showed a significant horizontal canopy position effect $(P=0.0021)$, foliar spray volume effect $(P<0.0001)$, and NPN treatment effect (covered vs. open) $(P=0.0393)$.
The NPN treatment effect results for leaves in June showed that, irrespective of the foliar spray volume, significantly more fluorescent pigment was deposited on leaves of control trees compared with leaves of NPN trees (4.8 and 3.1 FPC\%, respectively) (Table 2). A comparison of the $\mathrm{CV} \%$ of trees with different NPN (covered vs. open) treatments showed that the CV\% of leaves of control trees was better than that of leaves of NPN trees (59.6 vs. $80.5 \mathrm{CV} \%$ ), regardless of the foliar spray volume (Table 2).

For ICD\%, regardless of the NPN treatment (covered vs. open) or canopy position, the best ICD\% was obtained with the 7500 $\mathrm{L} \cdot \mathrm{ha}^{-1}$ foliar spray volume, which was similar to that of the $15,000 \mathrm{~L} \cdot \mathrm{ha}^{-1}$ foliar spray volume (73.2 vs. $77.7 \mathrm{ICD} \%$ ), but it was significantly better than the that of the 3500 $\mathrm{L} \cdot \mathrm{ha}^{-1}$ foliar spray volume $(94.4 \mathrm{ICD} \%)$. Regardless of the application volume or NPN treatment (covered vs. open), the leaf deposition analysis showed that the ICD\% on leaves on the outside of the tree canopy was significantly better than that of leaves on the inside of the tree canopy (79.8 and $83.8 \mathrm{ICD} \%$, respectively). However, regarding FPC $\%$ and $\mathrm{CV} \%$, the ICD\% of control trees was significantly better compared with NPN trees (79.4 and 84.2 ICD $\%$, respectively) (Table 2).

The ANOVA of the fruit deposition performed in June indicated that there was a significant interaction between the foliar spray volume, NPN treatment (NPN vs. covered), and vertical canopy position of leaves for FPC\% $(P=0.0342)$. The results of this interaction indicated that the $\mathrm{FPC} \%$ resulting from the different spray volumes at the different vertical canopy positions ranged between 5.5 FPC\% and 22.6 FPC\%. The results also showed a significant interaction between the foliar spray volume and horizontal canopy position of leaves $(P=$ 0.0018 ). For this interaction, it was seen that, regardless of the NPN treatment, the 3500 $\mathrm{L} \cdot \mathrm{ha}^{-1}$ application resulted in statistically similar FPC\% values on the inside (9.2 FPC $\%)$ and outside (6.9 FPC\%) of tree canopies. The inside value was similar to that of the $7500 \mathrm{~L} \cdot \mathrm{ha}^{-1}$ application on the inside (10.1 FPC \%) of the canopy. On the outside of the canopy, this volume resulted in an FPC\% of 15.3. This was statistically similar to the values obtained by the $15,000 \mathrm{~L} \cdot \mathrm{ha}^{-1}$ application on the outside (17.9 FPC\%) and inside $(16.9 \mathrm{FPC} \%)$ of the tree canopy. In this study, the significant interaction observed between the foliar spray volume and NPN treatments (covered vs. open) for FPC\% was most important $(P=0.0262)$.

The $15,000 \mathrm{~L} \cdot \mathrm{ha}^{-1}$ foliar spray volume resulted in the best $\mathrm{FPC} \%$ for fruit at both horizontal canopy positions (inside $=16.9$ $\mathrm{FPC} \%$ vs. outside $=17.9 \mathrm{FPC} \%$ ), regardless of the NPN treatment (covered or open) (Table 3). The $7500 \mathrm{~L} \cdot \mathrm{ha}^{-1}$ foliar spray volume resulted in an $\mathrm{FPC} \%$ of 15.26 for fruit on the outside of the tree canopy, which was similar to the $\mathrm{FPC} \%$ for fruit subjected to the $15,000 \mathrm{~L} \cdot \mathrm{ha}^{-1}$ foliar spray volume. However, for fruit on the inside of the tree canopy,
Table 1. Effects of nonpermanent netting (NPN) on deposition quantity (FPC\%), deposition uniformity (CV\%), and deposition quality (ICD\%) of foliar sprays on leaves of 'Nadorcott' mandarin trees with either 15,000 or $3500 \mathrm{~L} \cdot \mathrm{ha}^{-1}$ in Jan. 2018

\begin{tabular}{llcc}
\hline Treatments & FPC $\%$ & CV\% & ICD $\%$ \\
\hline Control & $8.8 \mathrm{a}^{\mathrm{z}}$ & $64.9 \mathrm{~b}$ & 61.5 \\
NPN & $6.1 \mathrm{~b}$ & $75.2 \mathrm{a}$ & 64.4 \\
$P$ & 0.0055 & 0.0062 & 0.1207 \\
\hline
\end{tabular}

${ }^{\mathrm{z}}$ Different letters in the same column denote significant differences between values at the $95 \%$ confidence level.

Table 2. Effects of nonpermanent netting (NPN) on deposition quantity (FPC\%), deposition uniformity (CV\%), and deposition quality (ICD $\%$ ) of foliar sprays on the leaves of 'Nadorcott' mandarin trees with $15,000,7500$, or $3500 \mathrm{~L} \cdot \mathrm{ha}^{-1}$ in June 2018.

\begin{tabular}{llcc}
\hline Treatments & FPC $\%$ & CV\% & ICD $\%$ \\
\hline Control & $4.8 \mathrm{a}^{\mathrm{z}}$ & $59.6 \mathrm{a}$ & $79.4 \mathrm{~b}$ \\
NPN & $3.1 \mathrm{~b}$ & $80.5 \mathrm{~b}$ & $84.2 \mathrm{a}$ \\
$P$ & 0.0035 & 0.0014 & 0.0393 \\
\hline
\end{tabular}

${ }^{\mathrm{z}}$ Different letters in the same column denote significant differences between values at the $95 \%$ confidence level.

the $7500 \mathrm{~L} \cdot \mathrm{ha}^{-1}$ foliar spray volume resulted in significantly poorer FPC\% (10.14). The poorest $\mathrm{FPC} \%$ for fruit resulted from the $3500 \mathrm{~L} \cdot \mathrm{ha}^{-1}$ foliar spray volume (inside $=$ 9.3 $\mathrm{FPC} \%$; outside $=6.9 \mathrm{FPC} \%$ ) $($ Table 3$)$. The FPC $\%$ for the $3500 \mathrm{~L} \cdot \mathrm{ha}^{-1}$ foliar spray volume was similar to that for fruit in the control group (8.8 $\mathrm{FPC} \%$ ) and fruit subjected to NPN treatments (7.4 FPC\%) (Table 3). With the $7500 \mathrm{~L} \cdot \mathrm{ha}^{-1}$ foliar spray volume, the FPC \% values for fruit differed significantly between the control and NPN treatments. The fruit from control trees had an $\mathrm{FPC} \%$ of 19.3 , and the fruit from trees subjected to NPN treatments had an FPC\% of 6.1 (Table 3). With the $15,000 \mathrm{~L} \cdot \mathrm{ha}^{-1}$ foliar spray volume, the $\mathrm{FPC} \%$ of fruit was similar for NPN and control trees (15.3 vs. $19.5 \mathrm{FPC} \%$ ).

The deposition uniformity (CV\%) results of fruit showed a significant interaction between foliar spray volume, NPN treatment, and vertical canopy position of fruit $(P=$ $0.0344)$. This interaction was most likely due to the different spray volumes, resulting in wide ranges of $\mathrm{CV} \%$ values at the different vertical positions. These values ranged from $26.7 \mathrm{CV} \%$ to $80.8 \mathrm{CV} \%$. Furthermore, a significant interaction between foliar spray volume and horizontal canopy position $(P=$ 0.0104 ) was observed for $\mathrm{CV} \%$, as was a significant interaction between foliar spray volume and NPN treatment $(P=0.0484)$. At the different horizontal canopy positions, varied results were observed in terms of the mean $\mathrm{CV} \%$. On the inside of the tree canopies, the $3500 \mathrm{~L} \cdot \mathrm{ha}^{-1}$ application resulted in a CV\% of 40.0 , which was statistically comparable to that of the $15,000 \mathrm{~L} \cdot \mathrm{ha}^{-1}$ application on the inside $(40.3 \mathrm{CV} \%)$ and outside (47.1 CV\%). On the outside of canopies, the $3500 \mathrm{~L} \cdot \mathrm{ha}^{-1}$ application resulted in a $\mathrm{CV} \%$ of 48.6. This was similar to results of the 7500 $\mathrm{L} \cdot \mathrm{ha}^{-1}$ application on the outside (55.8 CV\%) 
of the canopies. This volume performed the poorest when applied to the inside of the tree canopies (65.3 CV\%).

Results of the spray volume and NPN treatment interactions showed that the 15,000 $\mathrm{L} \cdot \mathrm{ha}^{-1}$ foliar spray volume resulted in similar $\mathrm{CV} \%$ for fruit from NPN and control trees (43.1\% and $44.3 \mathrm{CV} \%$ ) (Table 3). For fruit from control trees, the $7500 \mathrm{~L} \cdot \mathrm{ha}^{-1}$ foliar spray volume resulted in $\mathrm{CV} \%$ similar to that obtained with the $15,000 \mathrm{~L} \cdot \mathrm{ha}^{-1}$ foliar spray volume. However, with the NPN treatment, the $7500 \mathrm{~L} \cdot \mathrm{ha}^{-1}$ foliar spray volume resulted in the poorest $(70.3 \mathrm{CV} \%)$ ICD\% (Table 3 ). The $3500 \mathrm{~L} \cdot \mathrm{ha}^{-1}$ foliar spray volume performed similar to the $15,000 \mathrm{~L} \cdot \mathrm{ha}^{-1}$ foliar spray volume in terms of $\mathrm{CV} \%$ for both NPN and control treatments (47.8 and 40.9 CV\%) (Table 3).

The results of the deposition quality (ICD\%) analysis showed a significant vertical canopy position effect on fruit $(P=$ $0.0386)$ and a significant interaction between foliar spray volume and the horizontal canopy position of fruit $(P=0.0205)$. Furthermore, a significant interaction occurred between foliar spray volume and NPN treatment $(P=0.0157)$. Regarding the vertical canopy position effect, it was seen that the ICD \% for the bottom $(65.9 \mathrm{ICD} \%)$ and the ICD\% for the top (66.2 ICD\%) were statistically similar but better than the ICD $\%$ for the middle of the tree canopies (70.4 ICD\%). In terms of the volume and horizontal canopy position interaction, the $15,000 \mathrm{~L} \cdot \mathrm{ha}^{-1}$ application had the best ICD\% at the inside (57.7 ICD\%) and outside (58.2 ICD\%) of the canopies, with the next best ICD $\%$ achieved with $7500 \mathrm{~L} \cdot \mathrm{ha}^{-1}$ on the outside $(65.0 \mathrm{ICD} \%)$ of the canopies. The poorest ICD $\%$ was achieved with the $3500 \mathrm{~L} \cdot \mathrm{ha}^{-1}$ application, with an ICD\% of 74.1 on the inside of the canopy and 77.8 ICD\% on the outside of the canopy.

Regarding the volume and NPN treatment interaction, the poorest ICD\% values were recorded for fruit from trees (both NPN and control trees) sprayed with the $3500 \mathrm{~L} \cdot \mathrm{ha}^{-1}$ foliar spray volume. These poor values were similar to those of fruit from NPN trees that were sprayed with $7500 \mathrm{~L} \cdot \mathrm{ha}^{-1}$. The ICD\% was significantly better for fruit from control trees compared with fruit from the NPN trees (57.1 and 79.9 ICD\%, respectively) (Table 3). Regarding the CV\%, the 15,000 $\mathrm{L} \cdot \mathrm{ha}^{-1}$ foliar spray volume resulted in the best ICD\%, which was similar for fruit that underwent control and NPN treatments (54.9 and $60.9 \mathrm{ICD} \%$, respectively) (Table 3 ).

Insect pest prevalence. Overall, the experimental area had a low pest prevalence (Fig. 1). Nevertheless, meaningful results were obtained. The average number of weekly sterile male FCM catches in the control traps was considerably higher most weeks than average numbers found for both NPN treatments between January and June (Fig. 1A). However, a few sterile moths were caught in traps that were under the NPN (Fig. 1A). An increase in sterile male FCM activity was observed during the August to March NPN treatment when the nets had
Table 3. Mean deposition quantity (FPC\%), deposition uniformity (CV\%), and deposition quality (ICD\%) values for the significant foliar spray water volume $\times$ treatment interaction on the fruit from nonpermanent netting (NPN) or control trees sprayed with 15,000, 7500, or $3500 \mathrm{~L} \cdot \mathrm{ha}^{-1}$ in June 2018.

\begin{tabular}{lcccc}
\hline Foliar spray water volume $\left(\mathrm{L} \cdot h a^{-1}\right)$ & Treatments & FPC $\%$ & CV\% & ICD $\%$ \\
\hline 15,000 & Control & $19.5 \mathrm{a}^{\mathrm{z}}$ & $44.3 \mathrm{~b}$ & $54.9 \mathrm{~b}$ \\
& NPN & $15.3 \mathrm{a}$ & $43.1 \mathrm{~b}$ & $60.9 \mathrm{~b}$ \\
7500 & Control & $19.3 \mathrm{a}$ & $50.9 \mathrm{~b}$ & $57.1 \mathrm{~b}$ \\
& NPN & $6.1 \mathrm{~b}$ & $70.3 \mathrm{a}$ & $79.9 \mathrm{a}$ \\
3500 & Control & $8.8 \mathrm{~b}$ & $40.9 \mathrm{~b}$ & $74.1 \mathrm{a}$ \\
& NPN & $7.4 \mathrm{~b}$ & $47.8 \mathrm{~b}$ & $77.8 \mathrm{a}$ \\
$P$ & & 0.0262 & 0.0484 & 0.0157 \\
\hline
\end{tabular}

${ }^{\mathrm{z}}$ Different letters in the same column denote significant differences between values at the $95 \%$ confidence level.

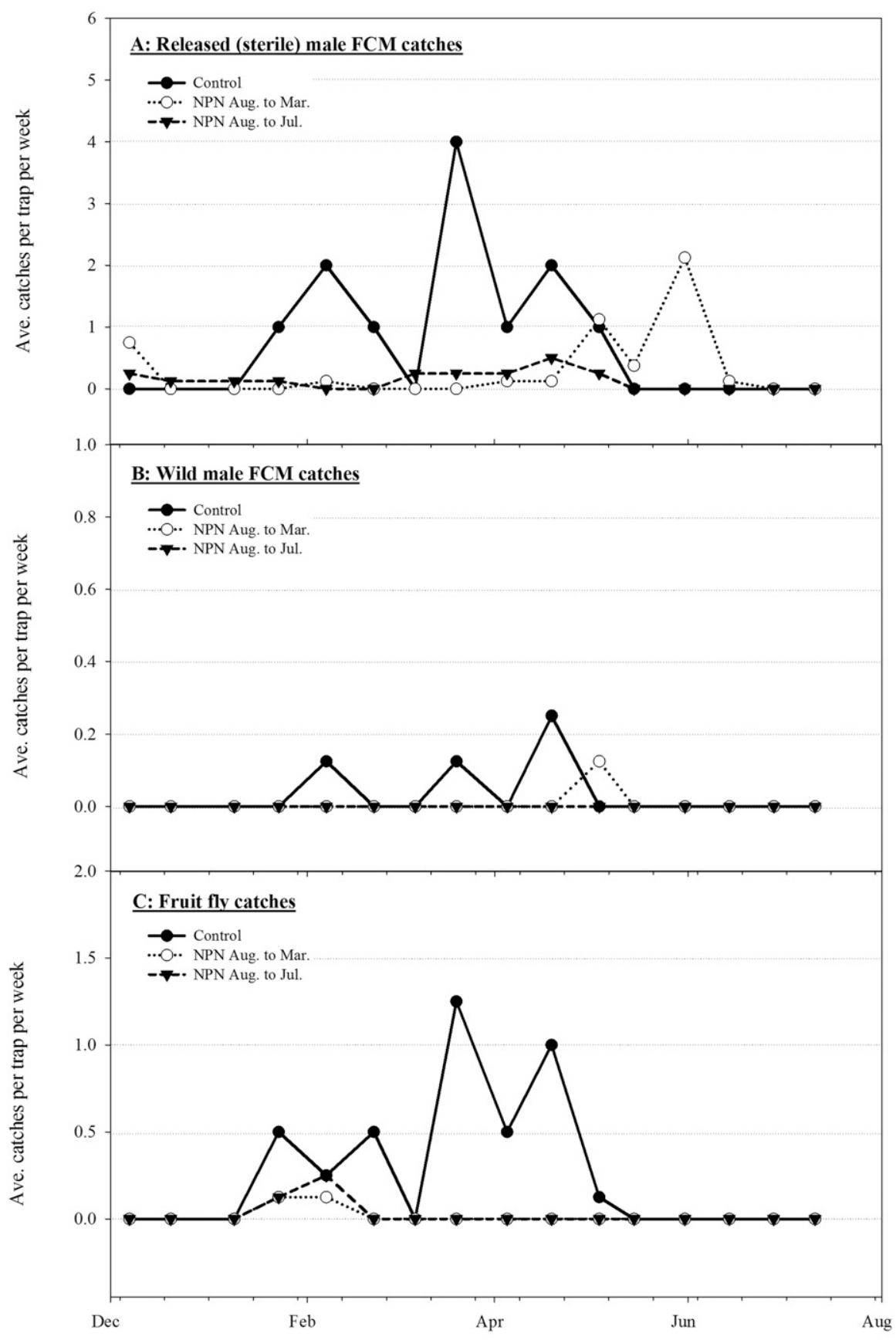

Date of trap monitoring

Fig. 1. The average number of (A) released (sterile) male false codling moths (FCM) (Thaumatotibia leucotreta), (B) wild male FCM, and (C) fruit flies (Ceratitis capitata) catches per trap per week for control and nonpermanent netting (NPN) treatments from Dec. 2017 to July 2018. 
been removed in March, thus leading to a peak in activity in July. The numbers of wild FCM caught in traps were very low, with four wild males trapped under control conditions and one wild male trapped under NPN treatment from August to March during the entire experiment.

No wild FCM males were caught in the NPN-treated trees when the netting was in place (Fig. 1B). Wild FCM males were only caught when using the control treatment and one of the NPN treatments after the netting had been removed (Fig. 1B). The same pattern for FCM was found for fruit flies; their numbers were greatly reduced beneath the NPN (Fig. 1C).

Leaf mineral nutrient concentrations. There were no significant differences between the concentrations of any of the macronutrients nitrogen $(\mathrm{N})$, phosphorous $(\mathrm{P})$, potassium $(\mathrm{K})$, calcium $(\mathrm{Ca})$, and magnesium $(\mathrm{Mg})$ in leaves of the control trees and the NPN-treated trees in March (Table 4). Regarding micronutrients, the concentrations of zinc ( $\mathrm{Zn})(P=0.0317)$ and iron $(\mathrm{Fe})(P=0.0041)$ were significantly higher (by $81 \%$ and $78 \%$, respectively) in leaves of the control trees compared with leaves of the NPN-treated trees (Table 4). There were no differences in the concentrations of sodium $(\mathrm{Na})$, manganese $(\mathrm{Mn})$, copper $(\mathrm{Cu})$, and boron (B) in the leaves of the control trees and leaves of the NPN-treated trees in March (Table 4).

Fruit yield. During the NPN August to November and NPN August to March treatments, the fruit yield (kg fruit per tree: $P=$ 0.0008 ; number of fruit per tree: $P=0.0002$ ) was significantly lower compared with that of the control and NPN August to July treatments (Table 5). The NPN August to March treatment resulted in the lowest fruit yield (69 $\mathrm{kg}$ and 765 fruit per tree), but it did not differ significantly from the fruit yield of the NPN August to November treatment $(72 \mathrm{~kg}$ and 782 fruit per tree) (Table 5). The NPN August to July treatment resulted in the highest fruit yield (102 kg and 1157 fruit per tree), but it did not differ significantly from the fruit yield of the control trees (95 kg and 1112 fruit per tree) (Table 5). Fruit yield of all the NPN treatments consisted of a greater amount of larger fruit (SC1 to SC1XX; not significant), whereas the fruit yield of the control trees consisted of a greater amount of smaller fruit (SC4 to SC5) (Fig. 2).

Fruit quality. The NPN treatments had no significant effects on the average fruit diameter, fruit rind color, juice content, and juice $\mathrm{Brix}^{\circ}$ compared with the control (Table 6). Fruit resulting from the NPN August to November treatment had significantly lower juice TA content compared with fruit resulting from the control and the NPN August to March and NPN August to July treatments (Table 6). The NPN August to November and the NPN August to July treatments had similar Brix $^{\circ}$ :TA ratios, but the Brix $^{\circ}$ :TA ratios were significantly higher compared with those of the control and NPN August to March treatments (Table 6). No seeds were found in any of the sampled fruit that underwent any treatment.
Fruit surface damage. Overall, light wind damage was most common (42\%), followed by undamaged or clean fruit $(36 \%)$ and fruit showing severe wind damage (19\%) (Fig. 3). Other types of damage noted were infrequently found, with $1.4 \%$ of fruit showing indications of pest damage and $1 \%$ of fruit showing chemical burn. The pest damage was highest

for leafhopper (Empoasca distinguenda Paoli) at $0.8 \%$, followed by bollworm (Helicoverpa armigera Hübner) at $0.3 \%$ and citrus thrips (Scirtothrips aurantii Faure) at $0.3 \%$. When comparing the wind damage of fruit from inside the canopy, the percentage of light wind damage was higher for fruit from the control treatment group compared those from the NPN

Table 4. Effects of nonpermanent netting (NPN) on leaf mineral nutrient concentration in Mar. 2018.

\begin{tabular}{lcccccc}
\hline Treatments & \multicolumn{6}{c}{ Leaf macronutrient concentration $\left(\mathrm{mg} \cdot \mathrm{g}^{-1}\right.$ leaf DW) } \\
\cline { 2 - 7 }$(\mathrm{n}=8)$ & $\mathrm{N}$ & $\mathrm{P}$ & $\mathrm{K}$ & $\mathrm{Ca}$ & $\mathrm{Mg}$ & \\
\hline Control & 31.1 & 2.0 & 12.3 & 37.1 & 3.1 \\
NPN & 32.9 & 1.9 & 12.9 & 38.1 & 3.3 & \\
$P$ & 0.0516 & 0.7873 & 0.6653 & 0.7413 & 0.6545 \\
& \multicolumn{7}{c}{ Leaf micronutrient concentration $\left(\mathrm{mg} \cdot \mathrm{kg}^{-1}\right.$ leaf DW $)$} & \\
\cline { 2 - 7 } & $\mathrm{Na}$ & $\mathrm{Mn}$ & $\mathrm{Zn}$ & $\mathrm{Fe}$ & $\mathrm{Cu}$ & $\mathrm{B}$ \\
\hline Control & 387 & 132 & $40 \mathrm{a}^{2}$ & $277 \mathrm{a}$ & 3.5 & 60 \\
NPN & 401 & 107 & $22 \mathrm{~b}$ & $156 \mathrm{~b}$ & 3.5 & 73 \\
$P$ & 0.7884 & 0.3623 & 0.0317 & 0.0041 & 1.0000 & 0.2109 \\
\hline
\end{tabular}

${ }^{\mathrm{z}}$ Different letters in the same column denote significant differences between values at the $95 \%$ confidence level.

Table 5. Effects of different nonpermanent netting (NPN) treatments on fruit yield of 'Nadorcott' mandarin.

\begin{tabular}{lcr}
\hline & \multicolumn{2}{c}{ Fruit yield } \\
\cline { 2 - 3 } Treatments $(\mathrm{n}=8)$ & $\mathrm{kg} \mathrm{per}$ tree & No. per tree \\
\hline Control & $95 \mathrm{a}^{\mathrm{z}}$ & $1112 \mathrm{a}$ \\
NPN August to November & $72 \mathrm{~b}$ & $782 \mathrm{~b}$ \\
NPN August to March & $69 \mathrm{~b}$ & $765 \mathrm{~b}$ \\
NPN August to July & $102 \mathrm{a}$ & $1157 \mathrm{a}$ \\
$P$ & 0.0008 & 0.0002 \\
\hline
\end{tabular}

${ }^{\mathrm{z}}$ Different letters in the same column denote significant differences between values at the $95 \%$ confidence level.

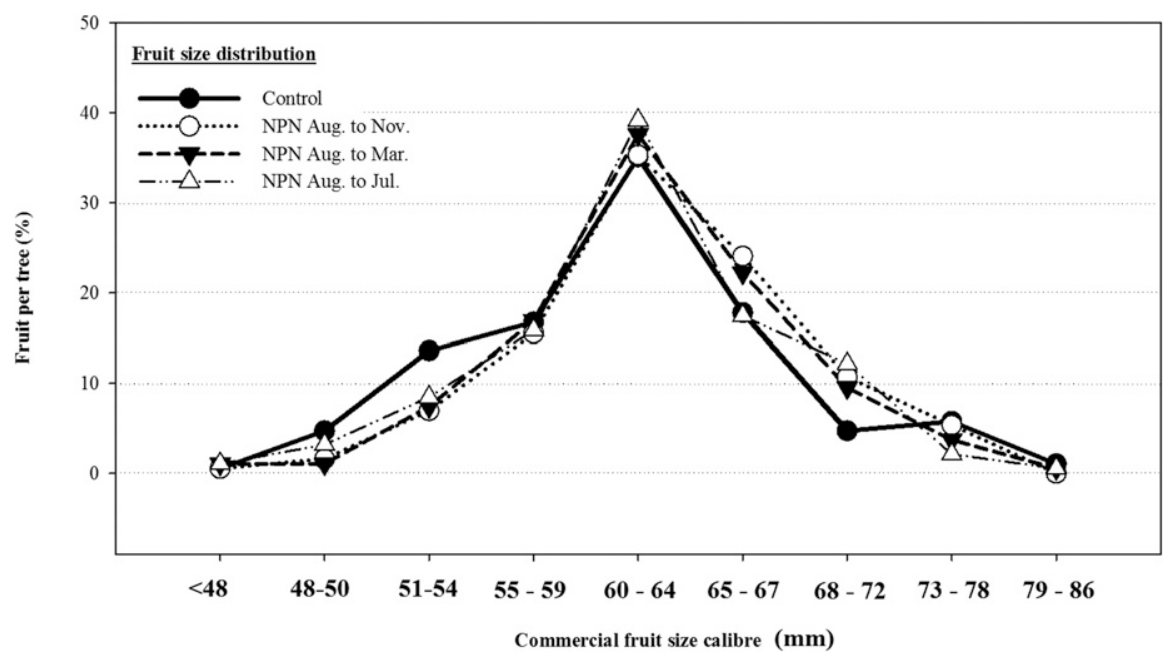

Fig. 2. Effects of different nonpermanent netting (NPN) treatments on the distribution of different commercial fruit size calibers (SC) on the yield of 'Nadorcott' mandarin.

Table 6. Effects of different nonpermanent netting (NPN) treatments on fruit quality of 'Nadorcott' mandarin.

\begin{tabular}{lllcccc}
\hline Treatments $(\mathrm{n}=8)$ & Diam & Color & Brix $^{\circ}$ & TA & Brix $^{\circ}$ :TA & Juice\% \\
\hline Control & 62 & 1.2 & 12.3 & $1.10 \mathrm{a}^{z}$ & $13.4 \mathrm{~b}$ & 61 \\
NPN August to November & 63 & 1.3 & 11.9 & $0.99 \mathrm{~b}$ & $15.1 \mathrm{a}$ & 62 \\
NPN August to March & 63 & 1.3 & 11.8 & $1.09 \mathrm{a}$ & $13.4 \mathrm{~b}$ & 63 \\
NPN August to July & 62 & 1.3 & 11.8 & $1.09 \mathrm{a}$ & $15.1 \mathrm{a}$ & 62 \\
$P$ & 0.8754 & 0.8520 & 0.1884 & 0.0387 & 0.0358 & 0.8741 \\
\hline
\end{tabular}

${ }^{\mathrm{z}}$ Different letters in the same column denote significant differences between values at the $95 \%$ confidence level. 


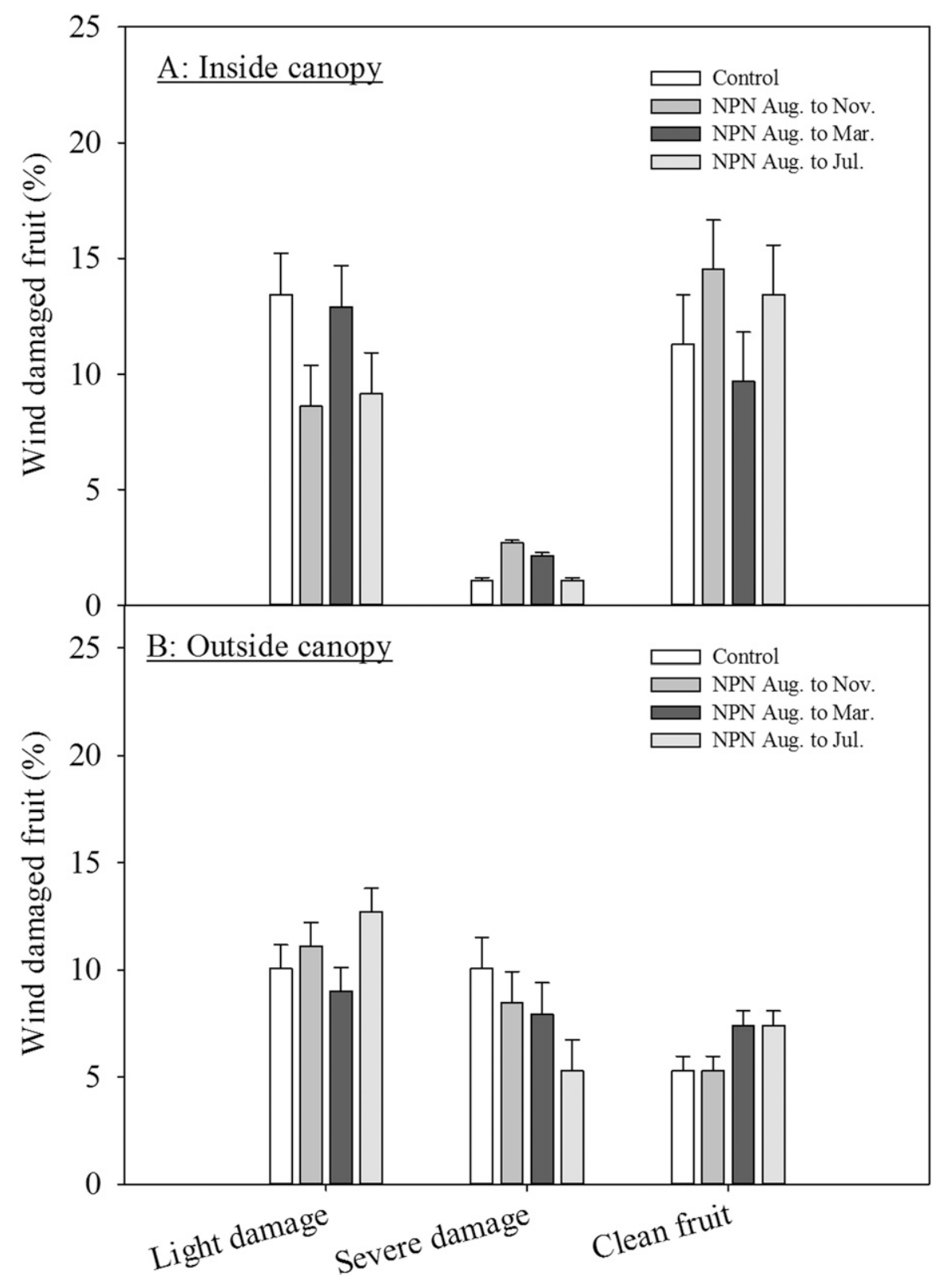

Fig. 3. Wind damage of fruit from (A) inside and (B) outside tree canopies of control and nonpermanent netting (NPN) treatments at the time of commercial harvest in July 2018.

treatment groups (Fig. 3). Inner canopy fruit that underwent the NPN August to November treatment had the highest percentage of clean fruit and the lowest percentage of light wind damage, but also the greatest percentage of severe wind damaged fruit (Fig. 3A). For the outer canopy fruit, the amount of fruit that experienced wind damage, particularly severe wind damage, was significantly greater compared to the fruit of the inner canopy. The NPN August to July treatment and NPN August to March showed an equal percentage of clean fruit, but the percentage with severe wind damage was lower (Fig. 3B).

The NPN August to November (22\%) and the NPN August to March (21\%) treatments resulted in similar fruit sunburn damage compared with the control (27\%) (Fig. 4). The longer NPN treatment (NPN August to July) resulted in significantly lower percentage $(9 \%)$ of sunburned fruit compared with the control, but similar percentage of sunburned fruit compared with the NPN August to March treatment (Fig. 4).

\section{Discussion}

The use of NPN reduced the efficacy of foliar spray applications for 'Nadorcott' mandarin trees by reducing the deposition quantity of foliar sprays in the tree canopy by up to $44 \%$, the deposition uniformity by up to $35 \%$ and the deposition quality by up to $40 \%$ compared with open trees. These effects were obtained with low and high foliar spray volumes during summer and on leaves in different canopy positions. During winter, NPN reduced the foliar spray deposition of a medium-volume foliar spray on leaves and fruit at different canopy positions. The practice of using NPN in orchards is popular for short periods in citrus-producing countries such as Australia, Chile, and the United States (personal communication with Etienne Rabe, Wonderful Citrus, CA, and Tim Grout, Citrus Research International), because of its efficacy for excluding bees and producing seedless fruit (Gambetta et al., 2013; Otero and Rivas, 2017). Producers would not be able to grow seedless fruit without NPN, which is a method that is safe for the environment. However, this is the first study to quantify the effects of NPN on foliar spray deposition on leaves and fruit in citrus tree canopies. Our results show that 'Nadorcott' mandarin growers who are considering using NPN would most probably have to adjust foliar spray applications of pesticides and fungicides, and possibly of plant growth regulator (PGR) and mineral nutrient foliar sprays, to increase the efficacy of targeted foliar sprays.

The trees in the experimental orchard were planted in sandy soil, for which it is standard practice to supply a proportion of certain mineral nutrients using low-volume foliar spray applications during spring and early summer (Lovatt, 2013), which is the period when the coverage of trees by NPN is recommended (Gambetta et al., 2013; Otero and Rivas, 2017). There were no differences in the concentrations of macronutrients in leaves of the trees subjected to control and NPN treatments. However, the concentrations of the micronutrients $\mathrm{Mn}(<23 \% ; P=$ $0.3623), \mathrm{Zn}(<81 \% ; P=0.0317)$, and $\mathrm{Fe}$ $(<78 \% ; P=0.0041)$ were lower in leaves of trees subjected to NPN treatments compared with the control treatment. Considering that NPN treatments reduced spray deposition quantity by $44 \%$, it could have been possible that a large portion of the foliar-applied micronutrients did not reach the trees. Furthermore, the deposition uniformity of foliar sprays in NPN was reduced by $35 \%$, and the translocation of $\mathrm{Zn}$ and $\mathrm{Mn}$ from sprayed to unsprayed leaves is usually minimal (Embleton et al., 1988; Swietlik, 1996). Micronutrients such as $\mathrm{Mn}$ and $\mathrm{Zn}$ have important roles in citrus (Embleton et al., 1988), particularly during spring and summer, and can be limiting to fruit quality, especially in sandy soils (Smith, 1966). For example, Swietlik (1996) reported an increase in fruit yield of grapefruit $(C$. paradisi) trees following $\mathrm{Zn}$ foliar spray when $20 \%$ or more leaves showed $\mathrm{Zn}$ deficiency symptoms. Embleton et al. (1988) showed that Mn deficiency in citrus leaves was correlated with reduced fruit size and a high Brix $^{\circ}$ :TA ratio in fruit juice at the time of harvest.

The long NPN treatment (August to July) reduced fruit sunburn damage by $17 \%$, but the outer canopy fruit experienced increased wind damage or scarring compared with the control. Except for lower TA found for fruit that underwent the shortest NPN treatment (August to November) and the higher $\mathrm{Brix}^{\circ}$ :TA ratio for fruit subjected to the two NPN treatments, the lower micronutrient concentrations in leaves did not impact other fruit quality attributes.

Short NPN treatments (August to March) reduced fruit yield by $33 \%$ and $37 \%$ compared with the control, most likely through a reduction in fruit set and/or an increase in 


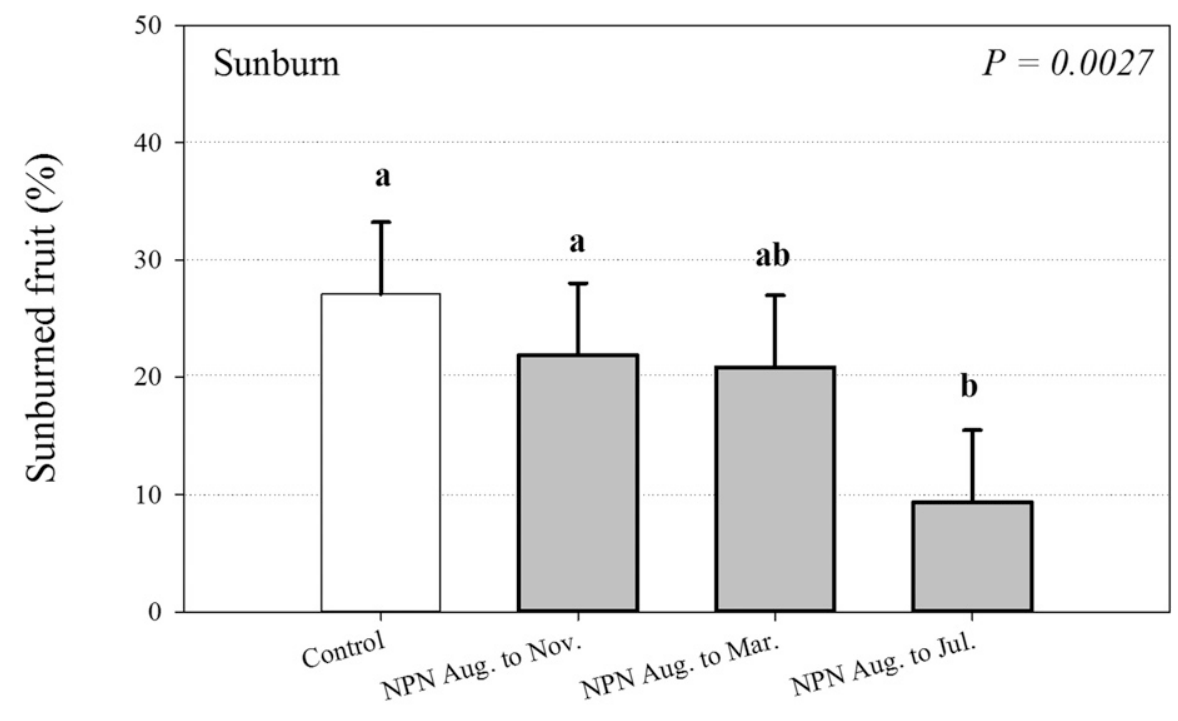

\section{Treatments}

Fig. 4. Effects of different nonpermanent netting (NPN) treatments on sunburn of 'Nadorcott' mandarin fruit.

fruit drop (Gambetta et al., 2013; Gravina et al., 2016; Otero and Rivas, 2017). Regarding 'Nadorcott' mandarin trees that were completely covered by NPN, Gambetta et al. (2013) reported that NPN reduced the fruit set, and Otero and Rivas (2017) showed that complete coverage of 'Nadorcott' mandarin tree canopies by NPN reduced fruit yield by $66 \%$. In this study, late removal of NPN treatments had no negative effects on fruit yield compared with the control treatment and confirmed that 'Nadorcott' mandarin is an obligate parthenocarp (Gambetta et al., 2013). Therefore, although NPN reduced the deposition quantity of foliar sprays, lower fruit yields with shorter NPN treatments were probably not related to the effects of NPN treatments on fruit set and foliar spray deposition, especially with $\mathrm{GA}_{3}$ sprays at petal drop to increase the fruit set (El-Otmani et al., 2000; Otero and Rivas, 2017). Trees covered by NPN for a period longer than March received the same foliar sprays during spring; this did not occur for trees covered by NPN for a shorter period. If the reduction in fruit yield was related to the lower foliar spray deposition, especially with $\mathrm{GA}_{3}$, then coverage of trees by NPN until fruit harvest would have had the same impact on fruit yield than shorter NPN treatments. In fact, longer NPN treatment probably would have excluded other important foliar sprays. However, the longer NPN treatment resulted in up to $38 \%$ more fruit per tree than shorter NPN treatments ( 1157 vs. 782 and $765 ; P=0.0002)$ and similar fruit yield compared with the control treatment ( 1157 vs. $1112 ; P=0.0002)$.

In other studies of the use of NPN for 'Nadorcott' mandarin, the application of $\mathrm{GA}_{3}$ to trees under NPN was able to compensate for the negative effects of NPN on the fruit set (Otero and Rivas, 2017). In this study, however, the lower fruit yield with shorter NPN treatments did not appear to be related to any negative effects of NPN on the fruit set or $\mathrm{GA}_{3}$ sprays. The fruit yield reduction was most likely caused by fruit drop that was exacerbated by the physical act of NPN removal. Shorter NPN treatments were removed at the end of November, close to the end of the physiological fruit drop period when fruitlets are particularly sensitive to abscission. To totally exclude bees, the NPN are draped over entire tree canopies and covered by sand or rocks at the base of the tree row. The weight of the NPN and the dragging action by which it is removed from tree rows place pressure on the tree and cause shaking, and, in some cases, breaking of tree limbs, fruiting branches, and twigs, which could exacerbate fruit drop. Of particular interest in this study is that 'Nadorcott' mandarin fruitlets were sensitive to drop until as late as March and only became insensitive to fruit drop when fruit were fully mature by July.

Although it did not appear that the lower related to the lower fruit yield or fruit quality, a lower leaf micronutrient concentration could affect fruit production in the long term or in other orchards, especially if nutritional sprays or application methods are not adjusted. The differences in the leaf micronutrient concentrations between NPN and control treatments were significant. However, the rate of nutrient applications in the experimental orchard was high and the concentrations of various mineral nutrients in leaves of trees subjected to the control and NPN treatments remained within the biological norm for citrus (Du Plessis et al., 1992; Du Plessis and Koen, 1992). In commercial orchards with insufficient rates of mineral nutrient applications, the effects of NPN on leaf micronutrient concentrations through the reduction in foliar spray deposition could negatively impact fruit production.

This experimental site did not have a high level of citrus pest infestation, and the disease micronutrient concentrations in leaves were pressure in the production region is known to be low due to the semi-arid and typical Mediterranean-type climate. It would be of interest to test NPN in other areas where pest populations are high or a particular species is known to be a problem. Nevertheless, the use of NPN in this study resulted in a clear reduction in moth trap catches in the case of both sterile and wild FCM when compared with the open controls, and NPN was able to help exclude larger citrus pests. Total exclusion is unlikely because it was still possible to capture released sterile FCM males and fruit flies under NPN, which may have been due to gaps forming in the nets as a result of wear and tear.

\section{Conclusion}

In general, the use of NPN in the production of 'Nadorcott' mandarin reduced foliar spray deposition on leaves and fruit and resulted in lower concentrations of certain micronutrients in leaves. For trees with NPN removed before July, the fruit yield was reduced by up to $37 \%$, but longer NPN treatment resulted in similar fruit yield compared with the control. The reduction in fruit yield after the shorter periods of tree coverage was not related to the effects of NPN on foliar spray deposition during spring and early summer or to lower leaf micronutrient concentrations. The lower fruit yield after short NPN treatments was most likely caused by fruit drop that was exacerbated by the physical removal of NPN. In orchards where the rate of mineral nutrient applications is insufficient, the effects of NPN on leaf micronutrient concentrations through reduction in foliar spray deposition could negatively impact fruit production during the long term. The use of NPN had no effects on commercial fruit quality attributes. When the NPN treatment was applied until fruit harvest, sunburn damage of fruit was reduced by $17 \%$. However, outer canopy fruit experienced increased wind damage or scarring. Therefore, citrus growers in very windy areas should remember this when considering the use of NPN. The use of NPN in this preliminary study did show an exclusionary effect on wild FCM males and a reduction in trap catches of sterile FCM males overall, which indicated that NPN can aid in preventing larger citrus pests from reaching the tree. However, successful exclusion of pests too large to fit through the holes in the netting would require strict application of the NPN such that the edges of the netting are buried beneath the soil surface surrounding the tree row to prevent ingress of such pests and constant general net maintenance. Because a very low number of fruit flies and sterile FCM males were caught within the netting, there could be difficulty achieving their total exclusion.

\section{Literature Cited}

Agustí, M., S. Zaragoza, H. Bleiholder, L. Buhr, H. Hack, R. Klose, and R. Staub. 1997. Adaptation de l'échelle $\mathrm{BBCH}$ à la description des stades phénologiques desagrumes du genre Citrus. Fruits 52:287-295. 
Barry, G.H. 2006. The quest for seedless Citrus fruit. Proc. Intl. Soc. Citricult. 1:346.

Bedford, E.C.G. 1998. Thrips, wind and other blemishes, p. 170-183. In: E.C.G. Bedford, M.A. van den Berg, and E.A. de Villiers (eds.). Citrus pests in the Republic of South Africa. $2^{\text {nd }}$ ed. Institute for Tropical and Subtropical Crops, Agricultural Research Council, Nelspruit, South Africa:.

Cohen, S., E. Raveh, Y. Li, A. Grava, and E.E. Goldschmidt. 2005. Physiological responses of leaves, tree growth and fruit yield of grapefruit trees under reflective shade screens. Scientia Hort. 107:25-35.

De Nettancourt, D. 1977. Incompatibility in Angiosperms. Springer, Berlin, Germany.

Department of Agriculture, Forestry and Fisheries (DAFF). 2015. Export standards and requirements: Part 2, soft citrus.

Du Plessis, S.F. and T.J. Koen. 1992. Leaf analysis norms for lemons [Citrus limon (L.) Burm.]. Proc. Intl. Soc. Citricult. 2:551-552.

Du Plessis, S.F., T.J. Koen, and W.J. Odendaal. 1992. Interpretation of Valencia leaf analysis by means of the $\mathrm{N} / \mathrm{K}$ ratio approach. Proc. Intl. Soc. Citricult. 2:553-555.

Du Toit, W.J. 1998. Fruit flies, p. 229-233. In: E.C.G. Bedford, M.A. van Den Berg and E.A. de Villiers (eds.). Citrus pests in the Republic of South Africa. 2nd ed. ARC Institute for Tropical and Subtropical Crops, South Africa.

El-Otmani, M., C.W. Jr. Coggins, M. Agusti, and C.J. Lovatt. 2000. Plant growth regulators in citriculture: World current uses. Crit. Rev. Plant Sci. 19:395-447.

Embleton, T.W., M. Matsumura, and I.A. Khan. 1988. Citrus zinc and manganese nutrition revisited. Proc. Intl. Soc. Citricult. 6:681-688.

Gambetta, G., A. Gravina, C. Fasiolo, C. Fornero, S. Galiger, C. Inzaurralde, and F. Rey. 2013. Self-incompatibility, parthenocarpy and reduction of seed presence in 'Afourer' mandarin. Scientia Hort. 164:183-188.

Gravina, A., G. Gambetta, F. Rey, and N. Guimaraes. 2016. Mejora de la productividad en mandarina
'Afourer' en aislamiento de polinizacion cruzada. Agrociencia Uruguay. 20:22-28.

Grout, T.G. and S.D. Moore. 2015. Citrus, p. $447-$ 499. In: G. L. Prinsloo and V. M. Uys (eds.) Insects of cultivated plants and natural pastures in Southern Africa. Entomological Society of Southern Africa, South Africa.

Hou, X. and B.T. Jones. 2000. Inductively coupled plasma/optical emission spectrometry, $\mathrm{p}$. 9468-9485. In: R.A. Meyers (ed.). Encyclopedia of analytical chemistry. John Wiley \& Sons Ltd, Chichester, UK.

Lovatt, C.J. 2013. Properly timing foliar-applied fertilizers increases efficacy: A review and update on timing foliar nutrient applications to citrus and avocado. HortTechnology 23: 536-541.

Manja, K. and M. Aoun. 2019. The use of nets for tree fruit crops and their impact on the production: A review. Scientia Hort. 246:110-122.

Mesejo, C., R. Yuste, C. Reig, A. MartínezFuentes, D.J. Iglesias, N. Muñoz-Fambuena, A. Bermejo, A. Germana, E. Primo-Millo, and M. Agustí. 2016. Gibberellin reactivates and maintains ovary-wall cell division causing fruit set in parthenocarpic Citrus species. Plant Sci. 247:13-24.

Moore, S.D. and V. Hattingh. 2012. A review of current pre-harvest control options for false codling moth in citrus in southern Africa. SA Vrugte J. 11:82-85.

Mupambi, G., B.M. Anthony, D.R. Layne, S. Musacchi, S. Serra, T. Schmidt, and L.A. Kalcsits. 2018. The influence of protective netting on tree physiology and fruit quality of apple: A review. Scientia Hort. 236: $60-72$.

Nadori, E.B. 2006. Nadorcott mandarin: A promising new variety. Proc. Intl. Soc. Citricult. (2004):356-359.

Newton, P.J. 1998. False codling moth Cryptophlebia leucotreta (Meyrick), p. 192-200. In: E.C.G. Bedford, M.A. van Den Berg and E.A. de Villiers (eds.). Citrus pests in the Republic of South Africa. 2nd ed. ARC Institute for
Tropical and Subtropical Crops, South Africa.

Otero, A. and F. Rivas. 2017. Field spatial pattern of seedy fruit and techniques to improve yield on 'Afourer' mandarin. Scientia Hort. 225:264-270

Pérez, M., B.M. Plaza, S. Jiménez, M.T. Lao, J. Barbero, and J.L. Bosch. 2006. The radiation spectrum through ornamental net houses and its impact on the climate generated. Intl. Symp. Greenhouse Cooling. 719:631-636.

Raveh, E., S. Cohen, T. Raz, D. Yakir, A. Grava, and E.E. Goldschmidt. 2003. Increased growth of young citrus trees under reduced radiation load in a semi-arid climate. J. Expt. Bot. 54:365-373.

Smith, P.F. 1966. Citrus nutrition, p. 174-207. In: Childers, N.F. (ed.). Temperate and tropical fruit nutrition. Hort. Pub. State Univ., New Brunswick, NJ.

Stamps, R.H. 2009. Use of colored shade netting in horticulture. HortScience 44:239-241.

Swietlik, D. 1996. Responses of citrus trees in Texas to foliar and soil $\mathrm{Zn}$ applications. Proc. Intl. Soc. Citricult. 8:772-776.

Van Zyl, J.G., P.H. Fourie, and G.C. Schutte. 2013. Spray deposition assessment and benchmarks for control of Alternaria brown spot on mandarin leaves with copper oxychloride. Crop Prot. 46:80-87.

Wachsmann, Y., N. Zur, Y. Shahak, K. Ratner, Y. Giler, L. Schlizerman, A. Sadka, S. Cohen, V. Garbinshikof, B. Giladi, and M. Faintzak. 2014. Photoselective anti-hail netting for improved citrus productivity and quality. Acta Hort. 1015:169-176.

Wright, G.C. 2007. Pollination of W. Murcott Afourer mandarins. Citrus Res. Rep. 12-13.

Zhou, K., D. Jerszurki, A. Sadka, L. Shlizerman, S. Rachmilevitch, and J. Ephrath. 2018. Effects of photoselective netting on root growth and development of young grafted orange trees under semi-arid climate. Scientia Hort. 238:272-280 